\title{
TAHSP:-
}

The Internet Joưnal of Allied Health Sciences and Practice

A Peer Reviewed Publication of the College of Health Care Sciences at Nova Southeastern University

Dedicated to allied health professional practice and education

http://ijahsp.nova.edu Vol. 11 No. 3 ISSN 1540-580X

\section{The Effect of a Single Session of Whole Body Vibration on Mobility, Lower Limb Joint Position Sense and Balance of Community Dwelling Older Adults}

\author{
Anne Jones, $\mathrm{PhD}{ }^{1}$ \\ Susan Gordon, $\mathrm{PhD}^{1}$ \\ Rebecca Sealey, $\mathrm{PhD}^{2}$
}

1. Discipline of Physiotherapy, James Cook University, Townsville, Queensland

2. Institute of Sport and Exercise Science, James Cook University, Townsville, Queensland

Australia

CITATION: Jones A, Gordon S, Sealey R. The Effect of a Single Session of Whole Body Vibration on Mobility, Lower Limb Joint Position Sense and Balance of Community Dwelling Older Adults. The Internet Journal of Allied Health Sciences and Practice. July 2013. Volume 11 Number 3.

\section{ABSTRACT}

Objectives: To determine the effects of a single episode of whole body vibration among community dwelling older adults on balance, mobility, and joint position sense. Methods: Thirty six adults over the age of 50 were recruited and underwent measurement of single limb stance for right and left legs, Timed Up and Go test, and joint position sense of the knee before and after a single episode of Whole Body Vibration (WBV) using a frequency of $6 \mathrm{~Hz}$, amplitude of $5 \mathrm{~mm}$, applied for ten minutes. Results: There was a statistically significant change in single limb balance for both the right and left legs following the single episode of WBV. There was no statistically significant change in timed up and go and joint position sense following WBV. Conclusions: A single episode of WBV for ten minutes, at $6 \mathrm{~Hz}$ and $5 \mathrm{~mm}$ peak to peak amplitude, had an effect on single limb balance, but no effect on joint position sense or mobility.

\section{INTRODUCTION}

As people age, deterioration in balance, mobility, and joint position sense contribute to an increased risk of falling. ${ }^{1}$ Approximately 28 to $35 \%$ of people aged 65 and over fall each year, increasing to 32 to $42 \%$ for those over 70 years of age. ${ }^{2}$ At least 20 to $30 \%$ of those who fall sustain an injury such as bruises, fractures, and disability, which reduce their overall mobility and subsequently their independence. ${ }^{3}$ The cost of falls to the health system is substantial. The projected health system cost of falls in Western Australia in 2021 is $\$ 174$ million. The reported corresponding costs in 2001-02 was $\$ 83$ million. ${ }^{4}$

Balance problems and lower extremity weakness have been associated with a 2 to 4 times increased risk of falls in community dwellers. ${ }^{5}$ Across all populations, impaired balance results in 3.2 times the risk of falling, and limited mobility results in 2.5 times the risk of falling. ${ }^{6}$ Single limb balance has been shown to be an indicator of poor balance and has been used to assess the risk of falling in the older population. ${ }^{7}$ Reported single limb balance mean values ( $95 \%$ confidence intervals) for 50 to 59 years of age are $41.2 \pm 10.2$ seconds, for the 60 to 69 years age group are 27.0 seconds ( 20.4 to 33.7$),{ }^{8,9}$ and 70 to 79 years of age 17.2 seconds (11.6 to 22.8). 8,10 The Timed Up and Go test is a sensitive indicator for poor mobility and therefore falls risk in the elderly. ${ }^{11}$ The mean normative values ( $95 \%$ confidence intervals) determined for the Timed Up and Go test via meta-analysis are 8.1 seconds (7.1 to 9.0 ) for 60 to 69 years and 9.2 seconds ( 8.2 to 10.2) for 70 to 79 years of age. ${ }^{9}$ Interventions that improve balance and mobility have the capacity to decrease fall rates, subsequent morbidity, and health spending. 
Most falls research has targeted people over 65 years where increased rates of falling have been established. Little falls research to date has been conducted in the 50 to 65 year age group. Interventions for this younger age group may elicit effective falls risk reduction via modification to intrinsic falls risk factors that contribute later to increased falls rates.

Whole body vibration (WBV) involves a person standing on an oscillating platform with adjustable frequency and amplitude. The vibrations created by the machine stimulate the nervous system to improve co-ordination, muscle strength, and balance. ${ }^{12}$ This system uses frequency, amplitude, and multiple directions of vibratory force and thus applies a different vibratory effect compared to vibration from vertical sources while a person is in sitting as found in industry. ${ }^{13}$ This type of whole body vibration is referred to as pivotal vibration involving side-to-side oscillations and does not cause spinal and disc injuries that have been found with vertical vibration.

Therapeutic use of whole body vibration has been shown to improve balance in nursing home residents with the average ages ranging from $72.4+/-4.9$ years to $81.9+/-6.9$ years, and to improve mobility in older persons average age of $62+/-6$ years. ${ }^{14-18}$ Different types of whole body vibration have been used including pivotal and vertical vibration. ${ }^{14,15,18,19} \mathrm{~A}$ range of different frequencies have been used with pivotal vibration from $10 \mathrm{~Hz}, 20 \mathrm{~Hz}, 26 \mathrm{~Hz}$ and $30 \mathrm{~Hz}$ and for vertical vibration frequencies ranging from 30 to $50 \mathrm{~Hz}$ have been reported. ${ }^{10-13}$ These studies utilised a range of whole body vibration session prescriptions with duration of vibration sets between one and three minutes, performed three times weekly for between six and12 weeks. 14,15,17 Significant improvement in balance has been reported as evidenced by enhanced limits of stability ${ }^{10}$ and Tinetti balance test 11,13 results. Therefore, it appears that a wide range of vibration frequencies is effective for improving balance in the untrained elderly population. Interestingly, despite evidence that 10 to $70 \mathrm{~Hz}$ vibration results in improvements in balance, the manufacturer of the Hypervibe pivotal vibration machine (used in the current study), recommends the use of 6 to $10 \mathrm{~Hz}$ for balance improvements.

While the above-mentioned studies provide evidence for the long term beneficial effects of vibration exercise on balance and mobility, only one previous study has investigated the acute effects of vibration on balance and mobility. It reported that one exposure (acute) of five, one minute periods of $30 \mathrm{~Hz}$ whole body vibration applied to eighteen healthy adults (24.3+/- 1.5yrs) did not alter joint position sense at the ankle or knee, did not alter balance (two foot stance and single limb stance with eyes open and closed), but did alter cutaneous sensation..$^{12}$ This acute reduction in cutaneous sensation did not affect balance in healthy young adults, perhaps due to the ability of healthy young adults to use their joint position sense to compensate for the loss of sensation. ${ }^{12}$ The ability to compensate for reduced sensation may not occur in older adults, therefore despite the benefits of longterm vibration training for improving balance in older adults, the acute effects need to be examined and considered for reasons of client safety. Further, the effect of whole body vibration on joint position sense of the lower limbs in the over 50 age group has not been established.

In contrast to previous research, this study investigated the acute effect of a single session of WBV on balance, mobility, and joint position sense in

1. a cohort of people who have not yet been identified at increased risk of falls (over 50 years)

2. using a low frequency $(6 \mathrm{~Hz})$ that has been recommended by the manufacturer to significantly improve balance.

\section{METHOD}

Ethical approval for this study was granted by the James Cook University Human Research Ethics Committee (H3976). A sample of convenience of English speaking participants aged over 50 years were recruited by verbal invitation and word of mouth from the staff of James Cook University, Australia. Participants were screened for exclusion criteria, as defined by the manufacturer (Hypervibe, Australia), which included severe cardiovascular disease, acute thrombosis, metal implants, a pacemaker, severe diabetes, infection in the previous four weeks, severe migraines, malignant tumours, stents implanted in the previous four weeks, epilepsy, gallbladder or kidney stones, recent wounds in the previous four weeks, acute inflammation or pain, or cognitive deficits.

The target age group was individuals over 50 years old to capture both the over 65 years category that have a known increased risk of falls and those approaching this age who may be developing risk factors for falls. ${ }^{2}$ All participants provided written informed consent.

\section{Vibration Intervention}

Participants completed a single, 10 minute session of WBV at $6 \mathrm{~Hz}$ and $5 \mathrm{~mm}$ amplitude, on a HyperVibe whole body vibration machine (Noosaville, Queensland, Australia). The machine provides pivotal vibration. An exercise science graduate was employed as the research assistant and trained in the protocol for the study. Participants were asked to remove their shoes, socks, and any items from their pockets which might dislodge during the vibration session, stand on the vibration platform with

(c) The Internet Journal of Allied Health Sciences and Practice, 2013 
their feet flat and facing forwards, shoulder width apart, and lightly hold the hand holds. ${ }^{18}$ The research assistant supervised the vibration sessions to ensure accuracy of session length, patient safety, and standardisation of participant position.

\section{Pre- and Post-Outcome Measures}

Joint Position Sense

Determining the target joint angle

Prior to the vibration session, a participant's dominant leg was identified by asking "Which leg do you use to kick a ball?" Participants were then positioned with their toes a standardised distance from a wall $(5 \mathrm{~cm})$. They were then asked to lunge forward with their dominant leg so that their knee was as close as possible to the wall. The angle of the knee was then measured using a universal goniometer as per Clarkson. ${ }^{19}$ Participants were asked to remember this target position as it was the position that they would be asked to reproduce from memory.

\section{Pre- and post-vibration Joint position sense assessment}

Participants were moved away from the wall position to remove visual cues and were asked to lunge forward to reproduce the same position as previously (pre 1). The participant then stood up for five seconds before repeating the procedure two more times (pre 2 and pre 3). Each position (pre 1,2,3) was measured by the one research assistant using the same universal goniometer and method. This protocol was repeated after the vibration session (post 1, 2 \& 3 measurements).

\section{Timed Up and Go Test}

Timed up and go was measured by asking the participant to sit in a chair with their back resting on the back of the chair. The participant was then asked to walk to a line marked three meters away, turn around, and walk back to sit in the chair with their back against the chair. ${ }^{9}$ Participants were allowed to practice once and were timed on their second attempt. The timed up and go test has been used as a measure for mobility and to discriminate between people on the basis of falls. It has been shown to be have reliability and validity with normative data having been established. ${ }^{9}$

\section{Single Limb Balance}

Single limb balance was measured by asking the participant to stand on their right leg with their eyes open for as long as they could, allowing a maximum of one minute. ${ }^{7}$ Time was measured using a stop watch from the point when their left foot left the ground until the participant returned the non-weight bearing foot to the ground, touched the weight bearing leg with the other foot to maintain balance, moved the weight bearing foot to maintain balance, or a minute was up. Alternate sides were assessed on three occasions for each side. All measurements were undertaken with the participant in bare feet, and the participant was instructed only to use their arms if they needed to save themselves from a fall. The research assistant stood near the participant to ensure that the participant did not fall and that they followed instructions.

\section{Data Analysis}

Sample size calculation with an a of 0.05 , power of 0.8 , and a moderate effect size (0.5) found that 34 participants were required. Knee joint position sense (JPS) was measured by calculating the absolute value of the target angle minus the actual angle..$^{20}$ From this, the mean was calculated as an average of these three measurements. ${ }^{21}$ This was then recorded as the mean pre and post. For single limb balance, the best time from each of the pre and post measures was taken as per previous studies. ${ }^{22,23}$ For each outcome measurement, a pre post two tailed t-test was performed with significance set at 0.05 .

\section{RESULTS}

Thirty-six participants were recruited to the study with the majority aged between 60 and 70 years (see Table 1). All participants were able to complete the pre and post measures and the vibration intervention without untoward incident.

Table 1. Mean \pm SD Participant Demographics

\begin{tabular}{|l|l|l|l|l|}
\hline Demographics & $\mathbf{5 0 - 5 9}$ years $(\mathbf{n}=\mathbf{1 0})$ & $\mathbf{6 0 - 7 0}$ years $(\mathbf{n}=\mathbf{2 3})$ & $\mathbf{7 0 - 8 0}$ years $(\mathbf{n}=\mathbf{3})$ & Total $(\mathbf{n}=\mathbf{3 6})$ \\
\hline Age (years) & $52.8 \pm 2.4$ & $62.1 \pm 1.7$ & $74.3 \pm 4.0$ & $60.6 \pm 6.2$ \\
\hline Females (\%) & $70 \%$ & $78 \%$ & $100 \%$ & $77.8 \%$ \\
\hline
\end{tabular}

A significant improvement in single leg balance time was evidenced for both the left $(p=0.02)$ and the right leg $(p=0.03)$ following the vibration intervention (Table 2). There was no significant difference between pre- and post- vibration mean scores for adoption of the target angle or the timed up-and-go test (Table 2). 
Table 2. Mean \pm Standard Deviation (Range) Values for Thirty-Six Healthy Older Adults, Before and After a 10-minute Vibration Intervention

\begin{tabular}{|l|l|l|l|}
\hline Variable & Pre-intervention & Post-intervention & p-value \\
\hline Joint position sense & $5.62 \pm 4.39$ & $4.96 \pm 5.02$ & 0.45 \\
absolute value (degrees) & $(0.3-19.0)$ & $(1.0-22.7)$ & \\
\hline Left single leg balance & $46.9 \pm 18.9$ & $49.4 \pm 16.5$ & 0.02 \\
(seconds) & $(7.85-60)$ & $(12.97-60)$ & \\
\hline Right single leg balance & $44.6 \pm 19.56$ & $48.5 \pm 18.3$ & 0.03 \\
(seconds) & $(10.69-60)$ & $(6.2-60)$ & \\
\hline Timed up-and-go (seconds) & $8.1 \pm 1.4$ & $8.1 \pm 1.6$ & 0.79 \\
& $(6.38-12.28)$ & $(6.16-14.03)$ & \\
\hline
\end{tabular}

\section{DISCUSSION}

This study provides evidence that an acute 10- minute episode of low-frequency $(6 \mathrm{~Hz})$ vibration significantly improved single-leg balance but had no effect on joint position sense and mobility in healthy older adults. These findings provide some evidence that participants who complete a single session of WBV are unlikely to be unsafe with respect to balance after participating in a WBV session.

\section{Intervention Effect}

Single-leg balance significantly improved immediately following the vibration intervention. Previous research has reported significant balance improvements following short-term (six weeks) higher frequency ( $15 \mathrm{to} 25 \mathrm{~Hz}$ ) vibration training; however, the results of the current study indicate that a single bout of low-frequency vibration is sufficient stimulus to improve short term balance in healthy, older persons. ${ }^{22}$ Potential mechanisms for the acute enhancing effect of vibration include increased lower limb muscle blood volume and blood flow velocity and enhanced neuromuscular activation and recruitment.23,24 These mechanisms, however, have been noted at higher frequencies, and it is feasible that these changes would occur at lower vibration frequencies. Further research is required to confirm this. The post-vibration measures were completed immediately after the vibration session, and further research is required to determine the length of time that this improvement lasts.

In contrast to previous research, this vibration intervention did not significantly improve mobility. ${ }^{17,18}$ It is important to note however that previous studies used functional exercises, higher frequencies, and longer program durations. ${ }^{17,18}$ Therefore, improvements in mobility may require a higher frequency and a longer program of vibration with the inclusion of functional movement. 17,18

Joint position sense at the knee did not significantly improve in this study, which is similar to the findings of Pollock et al who also used pivotal vibration. ${ }^{12}$ Given that their frequency was at $30 \mathrm{~Hz}$ and two different amplitudes of $4 \mathrm{~mm}$ and $8 \mathrm{~mm}$, it would appear that a single bout of pivotal whole body vibration at lower or higher frequencies does not induce changes in knee joint position sense. Previous literature has reported inhibition of stretch reflexes and of the H-reflex, but this does not appear to correlate with postural or balance issues following whole body vibration. ${ }^{25}$ Thus, further research needs to be undertaken to determine the neurophysiological mechanisms involved and to identify the frequencies and amplitudes which induce most change to balance, sensation, mobility, and joint position sense.

The participants in the current study aged 50 years and above demonstrated better balance but slower mobility when compared to published normal values. The pre-intervention mean score for both left and right single-leg balance in the current study exceeded those previously reported for both the 50 to 59 year olds and the 60 to 69 year age group. 8,10 Furthermore, approximately half of the participants achieved the maximum balance time of 60 seconds, indicating a reduced risk of falls related to poor balance in the current cohort. Further research in a cohort of known fallers needs to be undertaken.

While the average timed up and go score for the current participants was similar to that reported previously for 60 to 69 year age group by Bohannon et al, the completion time was slower than that reported by Isles et al for community dwelling women aged between 50 to 59 years $(6.44 \mathrm{~s})$ and 60 to 69 years $(7.24 \mathrm{sec}){ }^{26-28}$ The participants in the current study did not report any conditions that may have obviously affected gait or mobility; therefore, the variations on scores may be a result of a variation in the verbal commands given to the participants instead of participant ability. The Isles et al paper reported the timed up-and-go test to be performed "as quickly and safely as possible," while in the current study and Steffen et al the command "as quickly as possible" was not used. ${ }^{28}$ Instead, participants in the current study were encouraged to "walk at a comfortable pace" as previously reported by Podsiadlo and Richardson. ${ }^{29}$ The older age group reported a larger spread of mobility in the current study as compared to the 50 to 60 year age group, with the difference occurring at the minimum range. Despite this lower minimum

(c) The Internet Journal of Allied Health Sciences and Practice, 2013 
score in the older age group, only one participant in the current study recorded a timed up-and-go score greater than 13.5 seconds, which has been identified as being an indicator of falls risk. ${ }^{11}$ Therefore, as indicated by the balance scores, the current cohort appear to be at a low risk of falls related to balance or mobility deficits.

As far as the researchers are aware there is no previous evidence for the manufacturers' recommendation for the use of a frequency of $6 \mathrm{~Hz}$ to improve balance as used in this study. Based on the findings of this study, balance does improve at $6 \mathrm{~Hz}$ but there is no evidence to support the use of $6 \mathrm{~Hz}$ to improve mobility.

\section{Limitations}

The use of standing knee flexion measurements was included to provide a functional indicator of joint position sense. However, further research is required to determine its validity and reliability. This study did not set out to identify the mechanism responsible for improved single leg balance, and thus further research is required to understand this mechanism. This study used a population of community dwelling adults. It is not possible for the finding of improved single limb balance to be transferred to other populations such as those reporting neurological deficits or a history of falls.

This study is a pre-post intervention study without a control group. This means that there is a potential for bias in the findings. Given that the single limb balance did improve post WBV, there is the chance that this was due to the repeated practice nature of the test. However each participant had three trials of single limb balance prior to and following the WBV, and if practice was the cause of the improvement, it would be see in the pre-intervention measurements, which was not the case.

\section{CONCLUSION}

An acute 10-minute episode of $6 \mathrm{~Hz}$ pivotal vibration significantly improved single leg balance in this study but did not alter joint position sense or mobility in healthy, community dwelling adults over 50 years of age. In addition, this research has provided the first known evidence to support the manufactures recommendations of $6 \mathrm{~Hz}$ to improve balance. Further research is required to investigate if other vibration frequencies have the same acute effect on balance or alter JPS or mobility measures.

\section{Acknowledgements}

We would like to thank HyperVibe for the loan of the machines. HyperVibe has had no input into the data analysis, interpretation, or final conclusions. We would like to thank Ms Lauren Clarke and Ms Fiona Pringle for their assistance in data collection.

\section{REFERENCES}

1. Shaffer S, Harrison A. Aging of the somatosensory system: a translational perspective. Phys Ther. 2007;87(2):193-207. [PMID17244695]

2. Department of Aging and Life Course. WHO global report on falls prevention in older age: World Health Organization 2007.

3. Todd C, Skelton D. What are the main risk factors for falls among older people and what are the most effective interventions to prevent these falls? Copenhagen: World Health Organisation, Health Evidence Network Report 2004.

4. Hendrie D, Hall S, Legge M, Arena G. Injury in Westerna Australia: The health system costs of falls in older adults in Western Australia. Perth: Western Australian Government 2003.

5. Tinetti M, Speechley M, Ginter S. Risk factors for falls among elderly persons living in the community. N Engl J Med. 1988;319(26):1701-7. [PMID3205267]

6. Yoshida S. A global report on falls prevention. Epidemiology of falls: World Health Organization.

7. Jonsson E, Seiger A, Hirschfeld H. One-leg stance in health young and elderly adults: a measure of postural steadiness? Clinical Biomechanics. 2004;19:688-94. [PMID15288454]

8. Springer B, Marin R, Cyhan T, Roberts H, Gill N. Normative values for the unipedal stance test with eyes open and closed. Journal of Geriatric Physical Therapy. 2007;30(1):8-15. [PMID19839175]

9. Bohannon R. Reference values for the Timed up and go test: a descriptive meta-analysis. Journal of Geriatric Physical Therapy. 2006;29(2):64-8. [PMID16914068]

10. Bohannon R. Single limb stance times: a descriptive meta-analysis of data from individuals at least 60 years of age. Topics in Geriatric Rehabilitation. 2006;22(1):70-7.

11. Shumway-Cook A, Brauer S, Woollacott M. Predicting the probability for falls in community-dwelling older adults using the timed up and go test. Phys Ther. 2000;80(9):896-903. [PMID10960937]

12. Pollock R, Provan S, Martin F, Newham D. The effects of whole body vibration on balance, joint position sense and cutaneous sensation. European Journal of Applied Physiology. 2011;111(12):3069-77. [PMID21455611]

13. Bovenzi $M$, Hulshof $C$. An updated review of epidemiologic studies on the relationship between exposure to whole-body vibration and low back pain (1986- 1997). Int Arch Occup Environ Health. 1999;72(6):351-65. [PMID10473835] 
14. Cheung W, Mok H, Qin L, Sze P, Lee K, Leung K. High-frequency whole-body vibration improves balancing ability in elderly women. Arch Phys Med Rehabil. 2007;88(7):852-7. [PMID17601464]

15. Bruyere O, Wuidart M, Di Palma E, Gourlay M, Ethgen O, Richy F, et al. Controlled whole body vibration to decrease fall risk and improve health-related quality of life of nursing home residents. Arch Phys Med Rehabil. 2005;86(2):303-7. [PMID15706558]

16. Rehn B, Lidstrom J, Skoglund J, Lindstrom B. Effects on leg muscular performance from whole-body vibration exercise: a systematic review. Scand J Med Sci Sports. 2007;17(1):2-11. [PMID16903900]

17. Bautmans I, Van Hees E, Lemper J-C, Mets T. The feasibility of whole body vibration in institutionalised elderly persons and its influence on muscle performance, balance and mobility: a randomised controlled trial. Biomed Central Geriatrics. 2005;5(17):1-8. [PMID16372905]

18. Sealey R, Tope S. Effects of exercise interventions on physical condition and health of Vietnam Veterans. International Journal of Therapy and Rehabilitation. 2011;18(8):438-49.

19. Clarkson $\mathrm{H}$. Musculoskeletal assessment. Joint range of motion and manual muscle strength. $2 \mathrm{nd}$ ed. Philadelphia: Lippincott Williams and Wilkins; 2000.

20. Hopper D, Creagh M, Formby P, Goh S, Boyle J, Strauss G. Functional measurement of knee joint position sense after anterior cruciate ligament reconstruction. Arch Phys Med Rehabil. 2003;84:868-72. [PMID12808540]

21. Olsson L, Lund H, Henriksen M, Rogind H, Bliddal H, Danneskiold- Samsoe B. Test-retest reliability of a knee joint position sense measurement method in sitting and prone position. Advances in Physiotherapy. 2004;6:37-47.

22. Furness T, Maschette W. Influence of whole body vibration platform frequency on neuromuscular performance of community-dwellling older adults. Journal of Strength and Conditioning Research. 2009;23(5):1508-13. [PMID19620913]

23. Kerschan-Schindl K, Grampp S, Henk C, Resch H, Preisinger E, Fialka-Moser V, et al. Whole-body vibration exercise leads to alternations in muscle blood volume. Clin Physiol. 2001;21(3):377-82. [PMID11380538]

24. Torvinen S, Kannus $P$, Sievanen H, Jarvinen TA, Prasanen M, Kontulainen S, et al. Effects of a vibration exposure on musclular performance and body balance. Randomised cross-over study. Clinical Physiology and Functional Imaging. 2002;22(2):145- 52. [PMID12005157]

25. Rittweger J. Vibration as an exercise modality: how it may work, and what its potential might be. European Journal of Applied Physiology. 2010;108:877-904. doi: 10.1007/s00421-009-1303-3 [PMID20012646]

26. Bohannon R, Larkin P, Cook A. Decrease in timed balance test scores with aging. Phys Ther. 1984;60(7):1067-70. [PMID6739548]

27. Isles R, Low Choy N, Steer M, Nitz J. Normal values of balance tests in women aged 20-80. J Am Geriatr Soc. 2004;52:1367- 72. [PMID15271128]

28. Steffen T, Hacker T, Mollinger L. Age- and gender-related test performance in community-dwellling elderly people: sixminute walk test, berg balance sclae, timed up and go test, and gait speeds. Phys Ther. 2002;82(2):128-37. [PMID11856064]

29. Podsiadlo D, Richardson S. The timed "Up \& Go": a test of basic functional mobility for frail elderly persons. J Am Geriatr Soc. 1991;39(2):142-8. [PMID1991946]

\section{KEY TERMS}

Vibration, Balance, Joint Positions Sense 